\title{
PELATIHAN DIGITAL MARKETING UNTUK PENINGKATAN PEREKONOMIAN ANGGOTA KARANG TARUNA AL BARKAH DI KAMPUNG CICAYUR - TANGERANG
}

Pranoto*, Jasmani, I Nyoman Marayasa

Dosen Fakultas Ekonomi. Universitas Pamulang

Email* : pranoto140688@unpam.ac.id

\begin{abstract}
ABSTRAK
Tujuan yang ingin dicapai dalam kegiatan ini adalah : Melatih para pemuda menguasai teknik pemasaran melalui media sosial dan jaringan internet melui pembuatan konten yang menarik dengan sarana digital marketing agar dapat menghasilkan pendapatan yang signifikan untuk meningkatkan perekonomian para pemuda anggota karang taruna Al Barkah, Kampung Cicayur, Desa Cicalengka, Kecamatan Pagedangan Kota Tangerang - Banten.

Teknik pendekatan dilakukan dengan metode seminar dan simulasi secara lansung menggunakan perangkat computer dan gawai dari masing-masing peserta

Dengan pengabdian ini dapat membuka wawasan para pemuda Karang Taruna Al Barkah, Kampung Cicayur, Desa Cicalengka, Kecamatan Pagedangan Kota Tangerang - Banten, untuk dapat mengembangkan diri melalui pelatihan digital marketing , untuk meningkatkan kesejahteraan perekonomian dimasa yang akan datang.
\end{abstract}

\section{Kata Kunci : Marketing, Digital marketing, Peningkatan Ekonomi}

\section{PENDAHULUAN}

Dalam dunia bisnis, marketing atau pemasaran merupakan salah satu hal penting yang harus dilakukan. Sejalan dengan berkembangnya teknologi yang ada saat ini, strategi dalam melakukan pemasaran pun juga mulai berubah ke arah yang lebih modern. Jika dulu hanya menggunakan media promosi seperti surat kabar, majalah, radio, ataupun televisi, kini pemasaran sudah dilakukan dengan teknologi internet, atau yang kemudian dikenal dengan istilah digital marketing

Manfaat digital marketing adalah dapat menghemat biaya promosi, strategi promosi menggunakan media internet memang jauh lebih murah jika dibandingkan dengan menggunakan cara-cara konvensional seperti brosur, baliho, atau membuat iklan di radio dan televisi. Oleh sebab itu yang baru memulai bisnis dan ingin bisnis bisa cepat dikenal banyak orang, sebaiknya pilihlah strategi digital marketing untuk melakukan promosi

Digital marketing tidak hanya dapat membantu pemilik bisnis dalam menghasilkan klien. Tapi Digital marketing dapat pula menghemat anggaran iklan. 
Pelanggan atau customer merupakan salah satu hal penting dalam suksesnya sebuah bisnis. Oleh sebab itu, membangun kedekatan yang baik dengan pelanggan tentunya sangat penting, manfaat digital marketing yang berikutnya adalah dapat menjadi sarana penghubung yang baik dengan konsumen.

Mengingat media yang digunakan dalam pemasaran digital memungkinkan terjadinya percakapan melalui dunia maya, maka batasan ruang dan waktu akan menjadi lebih kecil dan keakraban antara penjual dan pelanggan pun bisa semakin mudah terjalin.

Berdasarkan pemaparan diatas, maka team PKM tertarik melakukan pelatihan kepada para pemuda anggota karang taruna dengan tema Pelatihan Digital Marketing Untuk Peningkatan Perekonomian Anggota Karang Taruna Al Barkah Di Kampung Cicayur - Tangerang

\section{RUMUSAN MASALAH}

Berdasarkan latar belakang diatas dapat dirumuskan permasalahan sebagai berikut : Bagaimana tingkat penguasaan teknologi para pemuda karang taruna dalam pemanfaatan media sosial sebagai sarana dalam memasarkan suatu produk melalui digital marketing?

\section{TUJUAN}

Tujuan yang ingin dicapai dalam kegiatan ini adalah : Melatih para pemuda menguasai teknik pemasaran melalui media sosial dan jaringan internet melui pembuatan konten yang menarik dengan sarana digital marketing agar dapat menghasilkan pendapatan yang signifikan untuk meningkatkan perekonomian para pemuda anggota karang taruna Al Barkah, Kampung Cicayur, Desa Cicalengka, Kecamatan Pagedangan Kota Tangerang - Banten.

\section{KEGIATAN}

Sasaran dari program Pengabdian Masyarakat ini para pemuda Karang Taruna Al-Barkah, Kampung Cicayur, Desa Cicalengka, Kecamatan Pagedangan Kota Tangerang - Banten. Jumlah peserta penyuluhan kurang lebih 20 orang Adapun pelaksanan dari kegiatan adalah sebagai berikut:

Hari : Jumat s/d Minggu

Tanggal/Bulan $\quad: 8-10$ Februari 2019

Waktu

: Pukul 09.00 - 15.00 WIB

Tempat

: Aula Kp. Cicayur, Kel. Cicalengka, Kec. Pagadegan Tangerang-Banten

\section{APLIKASI}

\section{A. Karang Taruna}

Karang Taruna adalah organisasi kepemudaan di Indonesia. Karang Taruna merupakan wadah pengembangan generasi muda nonpartisan, yang tumbuh atas dasar kesadaran dan rasa tanggung jawab sosial dari, oleh dan untuk masyarakat 
khususnya generasi muda di wilayah Desa / Kelurahan atau komunitas sosial sederajat, yang terutama bergerak dibidang kesejahteraan sosial. Sebagai organisasi sosial kepemudaan Karang Taruna merupakan wadah pembinaan dan pengembangan serta pemberdayaan dalam upaya mengembangkan kegiatan ekonomis produktif dengan pendayagunaan semua potensi yang tersedia dilingkungan baik sumber daya manusia maupun sumber daya alam yang telah ada. Sebagai organisasi kepemudaan, Karang Taruna berpedoman pada Pedoman

Dasar dan Pedoman Rumah Tangga di mana telah pula diatur tentang struktur penggurus dan masa jabatan dimasing-masing wilayah mulai dari Desa / Kelurahan sampai pada tingkat Nasional. Semua ini wujud dari pada regenerasi organisasi demi kelanjutan organisasi serta pembinaan anggota Karang Taruna baik dimasa sekarang maupun masa yang akan datang.

Karang Taruna beranggotakan pemuda dan pemudi (dalam AD/ART nya diatur keanggotaannya mulai dari pemuda/i berusia mulai dari 11 - 45 tahun) dan batasan sebagai Pengurus adalah berusia mulai 17 - 35 tahun.

Karang Taruna didirikan dengan tujuan memberikan pembinaan dan pemberdayaan kepada para remaja, misalnya dalam bidang keorganisasian, ekonomi, olahraga, ketrampilan, advokasi, keagamaan dan kesenian.

\section{B. Pemasaran}

Pemasaran merupakan sebuah konsep kunci keberhasilan suatu bisnis dimana pemasaran dengan memperhatikan keinginan dan pemenuhan kebutuhan pelanggan untuk tercapainya target penjualan yang ditetapkan sehingga memberi dampak positif bagi perkembangan usaha suatu perusahaan di tengah persaingan bisnis yang begitu ketat dewasa ini. Pemahaman pemasaran bagi pemasar sangat penting untuk pengenalan kebutuhan dan keinginan pelanggan, penentuan pasar sasaran mana yang dapat dilayani, serta merancang produk dan program yang tepat dalam melayani pasar sehingga dapat mengoptimalkan penjualan.

Menurut Kotler dan Keller (2012:5) mendefinisikan tentang pemasaran sebagai berikut "Pemasaran adalah suatu proses sosial dan manajerial yang membuat individu maupun kelompok memperoleh apa yang mereka berikan dan yang mereka inginkan dengan menciptakan, menawarkan dan secara bebas mempertukarkan produk dan jasa yang bernilai dengan pihak lain". Sedangkan menurut Bilson Simamora (2009:149) mengatakan bahwa "Pemasaran memiliki arti yang sama sekali berbeda dengan penjualan". Pemasaran juga tidak sekedar periklanan dan bentuk-bentuk promosi lainnya. Namun, setiap hari kita selalu menjadi sasaran pemasaran dari berbagai produk.

Kemudian Basu Swastha (2008:17) menyatakan "Pemasaran adalah sistem keseluruhan dari kegiatan usaha/bisnis yang ditujukan untuk merencanakan, menentukan harga, mempromosikan dan mendistribusikan barang dan jasa yang dapat memuaskan kebutuhan pembeli yang ada maupun pembeli potensial.".

Dari pendapat beberapa ahli dapat diketahui bahwa pemasaran adalah suatu proses penyusunan komunikasi terpadu yang bertujuan untuk memberi informasi mengenai barang atau jasa dalam kaitannya dengan memuaskan konsumen- 
konsumen dengan mengharuskan pemasar melakukan sasaran melalui tiga langkah utama yaitu:

a. Mengidentifikasi dan memilah-milah kelompok pembeli yang berbedabeda yang mungkin meminta produk atau bauran pemasaran tersendiri (segmentasi pasar).

b. Memilih satu atau lebih segmen pasar dengan tujuan untuk dimasuki pembidikan pasar.

c. Membentuk dan mengkomunikasikan manfaat dengan produk lain di pasar (penetrasi pasar).

\section{Digital marketing}

Digital Marketing atau Pemasaran digital adalah suatu usaha untuk mempromosikan sebuah merek dengan menggunakan media digital yang dapat menjangkau konsumen secara tepat waktu, pribadi, dan relevan.

Tipe pemasaran digital mencakup banyak teknik dan praktik yang terkandung dalam kategori pemasaran internet. Dengan adanya ketergantungan pemasaran tanpa internet membuat bidang pemasaran digital menggabungkan elemen utama lainnya seperti ponsel, SMS (pesan teks dikirim melalui ponsel), menampilkan iklan spanduk, dan digital luar.

Pemasaran digital turut menggabungkan faktor psikologis, humanis, antropologi, dan teknologi yang akan menjadi media baru dengan kapasitas besar, interaktif, dan multimedia. Hasil dari era baru berupa interaksi antara produsen, perantara pasar, dan konsumen. Pemasaran melalui digital sedang diperluas untuk mendukung pelayanan perusahaan dan keterlibatan dari konsumen.

\section{E-mail}

\section{Pemasaran internet}

Pemasaran melalui e-mail/surel disebut e-mail komersial. Penggunaan email dalam bisnis dapat membantu pengiriman informasi (promosi) mengenai produk atau jasa pada receiver (penerima pesan). CAN-SPAM Act adalah sebuah hukum yang menetapkan aturan-aturan untuk e-mail komersial

Persyaratan utama CAN-SPAM Act :

- Dilarang menggunakan informasi header palsu atau menyesatkan Mengindetifikasi bisnis secara akurat.

- Dilarang menggunakan baris subjek yang menipu Baris subjek harus mencerminkan isi pesan.

- Identifikasi pesan sebagai iklan Iklan harus diungkapkan dengan jelas dan mencolok.

- Menyertakan lokasi keberadaan pengirim kepada penerima pesan Mengikutsertakan alamat yang valid berupa pos fisik. Pos tersebut harus terdaftar pada Postal Service.

- Memantau orang lain yang mengatasnamakan perusahaan utama Menyewa perusahaan lain untuk menangani pemasaran e-mail harus didasari atas tanggung jawab dengan mematuhi hukum yang berlaku. 


\section{Sender Score}

Sender Score adalah sebuah layanan gratis, di mana algoritma Sender Score memberi rating terhadap reputasi setiap alamat IP server mail dengan skala 0-100. Dengan mengumpulkan data dari lebih 60 juta mailbox di ISP-ISP besar mereka merekam apakah orang sering melakukanunsubscribe atau melaporkan spam dari pengirim email tertentu, dan kemudian memberikan skor pengirim berdasarkan pemantauan tersebut. Sender Score akan terus berubah tergantung pada kebiasaan mengirim email dan respon dari para penerima.

Sender Score adalah sebuah angka penting untuk tetap berada di posisi teratas, karena mail server akan sering memeriksa Sender Score sebelum memutuskan apa yang akan mereka lakukan terhadap suatu email. Semakin rendah Sender Score, maka semakin sulit untuk suatu email masuk ke inbox seseorang. Ada banyak hal yang bisa berdampak pada keterkiriman email, tetapi laporannya menyatakan bahwa $83 \%$ email tidak terkirim ke inbox, disebabkan karena reputasi pengirim yang buruk.

Bahkan jika sebuah jaringan email atau ISP tidak menelusuri suatu Sender Score untuk menentukan apakah mereka akan mengirim email tersebut atau tidak, namun faktor-faktor yang digunakan dalam menentukan Sender Score mirip dengan yang digunakan oleh jaringan-jaringan email dan ISP untuk menentukan reputasi pengirim. Oleh karena itu, skor ini merupakan alat reputasi pengirim email yang sangat baik dan gratis untuk memastikan menyadari dan memiliki kesempatan untuk memperbaiki setiap masalah keterkiriman

\section{Pemasaran tanpa internet}

- SMS

Salah satu pesan teks melalui ponsel. Pemasaran ini dimulai sejak tahun 2000-an di beberapa negara seperti Eropa, Amerika Utara, dan Asia. Pada tahun 2005 alat komunikasi seluler (ponsel) menjadi bentuk pemasaran yang sah di seluruh dunia.

- Iklan banner

Iklan yang muncul pada halaman web untuk mempromosikan blog atau situs kliennya.

\section{Strategi pemasaran digital}

Terdapat dua strategi pada pemasaran digital berdasarkan cara pengiriman yaitu tarik dan dorong, masing-masing memiliki kelebihan dan kekurangan.

\section{Tarik}

Pemasaran digital ini melibatkan konsumen untuk mencari, melihat, dan mengambil informasi secara langsung melalui situs atau mesin pencari. Konsumen berperan aktif dalam mencari informasi yang dibutuhkan, biasanya terletak pada situs atau website, blog, audio streaming, dll. 
Kelebihan :

- Tidak memerlukan teknologi canggih untuk mengirimkan konten, hanya diperlukan untuk menyimpan atau menampilkannya.

- Tidak ada batasan dari segi konten atau ukuran berkas karena semua ditentukan oleh konsumen.

- Kebebasan media yaitu perusahaan bebas menggunakan metode apa pun untuk menarik konsumen.

Kekurangan :

- Tidak ada personalisasi untuk menjaga pengunjung datang kembali.

- Bersifat pasif karena mengandalkan mesin pencari.

- Terbatasnya kemampuan untuk mengukur hasil pada konsumen.

\section{Dorong}

Pemasaran digital ini memberikan informasi kepada konsumen dengan melihat atau menerima iklan digital secara aktif. Informasi dapat datang dalam bentuk e-mail, panggilan ponsel, SMS (pesan teks dikirim melalui ponsel),MMS (pesan multimedia), RSS (format feed web yang mendistribusikan berita dan informasi), dan lain-lain

Kelebihan :

- Memilih sasaran konsumen secara khusus.

- Pesan yang dikirim dapat disesuaikan dengan kriteria konsumen.

- Melakukan pelacakan rinci tentang pilihan konsumen.

Kekurangan :

- Memerlukan mekanisme dalam pengiriman pesan.

- Pesan dapat dicegah oleh konsumen.

- Timbulnya isu privasi akibat konsumen tidak tertarik dengan e-mail atau SMS yang bersifat promosi dan iklan.

\section{E. Solusi pemasaran digital}

Solusi pemasaran digital meliputi penggunaan berbagai saluran pengiriman yang meliputi teknik tarik dan dorong. Hal ini digunakan untuk memperluas dukungan pelayanan perusahaan dan keterlibatan konsumen. Perusahaan perlu menjadi adaptif dan responsif dalam memenangkan konsumen. Pertahanan dalam paradigma baru ini, perusahaan harus membuat komitmen yang kuat untuk pemasaran digital melalui investasi baru dalam teknologi dan inovasi. Berakhir pada solusi pemasaran yang ideal berupa mencapai, retensi, dan pendapatan. ${ }^{[9]}$ Aturan dalam pemasaran digital :

- Menargetkan satu segmen dan menciptakan komunitas virtual.

- Memperluas peran merek dalam portofolio secara global.

- Gunakan harga yang kreatif.

- Mengutamakan desain bagi konsumen.

- Gunakan eksperimentasi yang bersifat adaptif.

- Menemukan kembali riset pemasaran dan pemodelan sebagai penciptaan pengetahuan. 


\section{F. Langkah-langkah pemasaran digital}

Dalam aktivitas pemasaran digital terdapat istilah AIDA (Awareness, Interest, Desire, dan Action), khususnya dalam proses memperkenalkan produk atau jasa ke pasar (konsumen).

1. Awareness (Kesadaran)

Dalam ranah digital, pemasar membangun kesadaran konsumen dengan memasang iklan terlebih dahulu di media online, seperti Detik.com.

2. Interest (Ketertarikan)

Ketertarikan muncul setelah membangun kesadaran pada konsumen. Sistem offline, konsumen langsung mencari informasi di pasar. Sistem online, konsumen mencari tahu tentang produk melalui mesin pencari (Google, Yahoo! dll) dan jejaring sosial (Facebook, Twitter dll).

3. Desire (Keinginan)

Timbul keyakinan pada konsumen sehingga berkeinginan untuk mencoba produk atau jasa. Sistem online ditandai dengan mencari keterangan lengkap tentang produk atau jasa melalui situs web.

4. Action (Tindakan)

Tahap terakhir sebagai penentuan dari pihak konsumen terhadap produk atau jasa.

\section{G. Kunci sukses pemasaran digital}

- Harus memperhatikan istilah pada AIDA (Awareness, Interest, Desire, dan Action).

- Pasar adalah tempat komunikasi dua arah. Untuk memperoleh komunikasi tersebut merek harus melakukan positioning terlebih dahulu, dapat melalui berbagai media (Forum, blog, dan lain-lain) dan yang paling efektif ialah melalui jejaring sosial.

\section{STRATEGI}

Perkembangan zaman mengharuskan sumber daya manusia menguasai ilmu pengetahuan dan teknologi dalam pelatihan ini para peserta di latih untuk dapat membuat konten yang menarik dalam membuat penawaran barang dalam bentuk digital, kemudian di arahkan untuk memasarkan barang tersebut melalui media sosial dan jaringan internet.

\section{PENUTUP}

Pelaksanaan kegiatan pengabdian masyarakat oleh lembaga penelitian dan pengembangan masyarakat (LPPM) Universitas Pamulang yang dilakukan oleh dosen-dosen program studi manajemen telah berjalan dengan lancar dan mendapat sambutan hangat dari tempat pelaksanaan kegiatan ini yaitu para pemuda Karang Taruna Al Barkah, Kampung Cicayur, Desa Cicalengka, Kecamatan Pagedangan Kota Tangerang - Banten

Dengan pengabdian ini dapat membuka wawasan para pemuda Karang Taruna Al Barkah, Kampung Cicayur, Desa Cicalengka, Kecamatan Pagedangan 
Kota Tangerang - Banten, untuk dapat mengembangkan diri melalui pelatihan digital marketing, untuk meningkatkan kesejahteraan perekonomian dimasa yang akan datang.

\section{DAFTAR REFERENSI}

Keller dan Amstrong, 2012. "Prinsip-prinsip Pemasaran”, Edisi Kedua Belas, Jilid Satu, Erlangga, Jakarta.

Kotler, Philip, 2012.“Manajemen Pemasaran”, Edisi Keempat belas, PT. Indeks, Jakarta.

Kotler, Philip. dan Kevin Lane Keller, 2012."Manajemen Pemasaran”, PT Macaman Jaya Cemerlang, Jakarta.

Simamora, Bilson, 2009. "Panduan Perilaku Konsumen”, Penerbit PT. Gramedia Pustaka Utama, Jakarta.

, 2012. “Panduan Riset Dan Perilaku Konsumen”, PT. Gramedia Pustaka Utama, Jakarta.

Swastha, Bashu dan T. Handoko, 2005. "Manajemen Pemasaran Moderen”, BPFE, Yogyakarta.

https://id.wikipedia.org/wiki/Karang_Taruna

https://id.wikipedia.org/wiki/Pemasaran_digital

https://indonesiago.digital/manfaat-digital-marketing-untuk-bisnis-anda/ 
DOKUMENTASI FOTO KEGIATAN
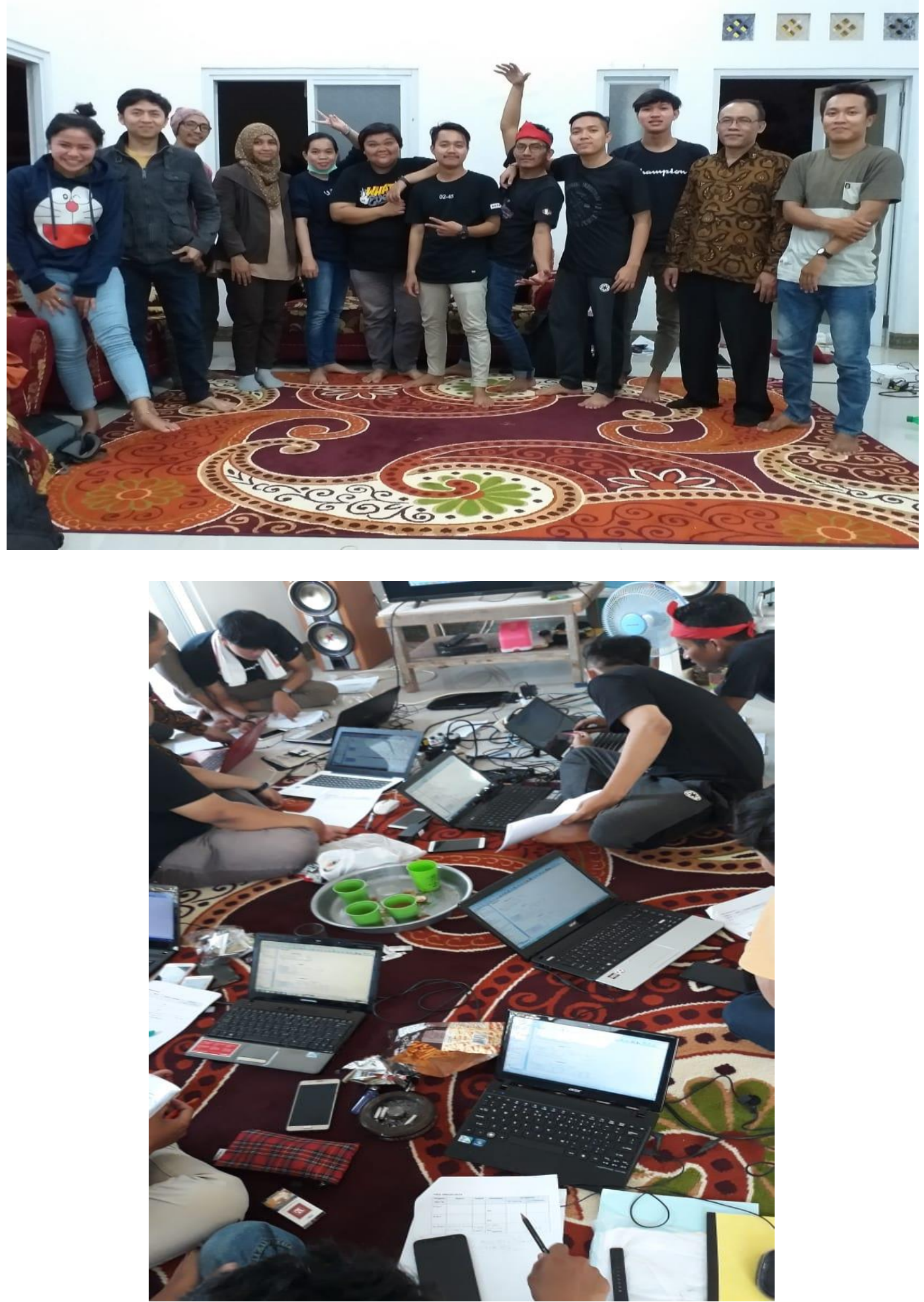